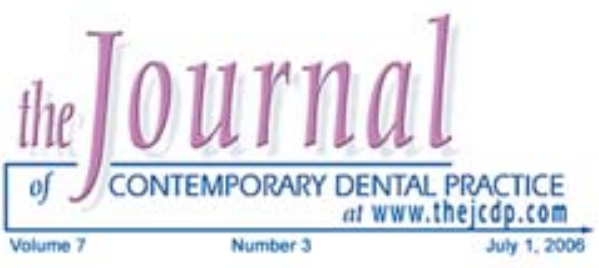

\title{
Oral Surgery with Fibrin Sealants in Patients with Bleeding Disorders: A Case Report
}
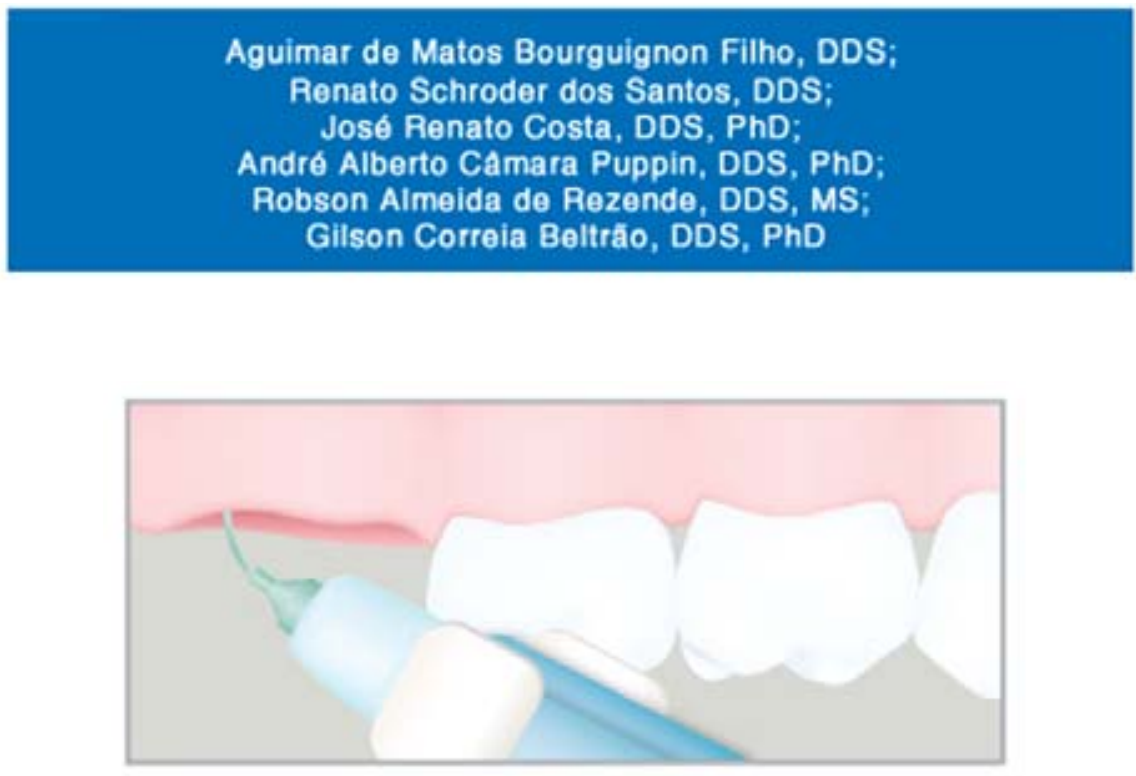

\begin{abstract}
Surgical treatment of patients with bleeding disorders requires careful planning. The use of fibrin sealants following a dental extraction in a patient with von Willebrand's disease is presented in this report. A female patient with von Willebrand's disease had an extraction of a maxillary right third molar. After evaluation by the surgeon and the hematologist, the surgery was performed with a topical application of fibrin sealant and systemic administration of antifibrinolytic drugs. Hemostasis was obtained without replacement of plasma clotting factor. New techniques of achieving hemostasis in patients with bleeding disorders using fibrin sealants have been successfully used in oral surgery without replacement of plasma clotting factors or changes in anticoagulant therapy.

Keywords: Fibrin sealants, oral surgery, von Willebrand's disease, bleeding disorder

Citation: Filho AMB, Dos Santos RS, Costa JR, Puppin AAC, De Rezende RA, Beltrão GC. Oral Surgery with Fibrin Sealants in Patients with Bleeding Disorders: A Case Report. J Contemp Dent Pract 2006 July;(7)3:106-112.
\end{abstract}

(C) Seer Publishing 


\section{Introduction}

Bleeding episodes can result from hereditary or acquired alterations in blood vessels, platelets, clotting factors, or in the fibrinolytic mechanism. Clotting factor deficiencies, such as those found in hemophilia A (factor VIII), hemophilia B (factor IX), and in the von Willebrand's disease (factor VIII), are examples of such hereditary disorders. Patients with acquired bleeding disorders usually have renal and hepatic disease or make use of anticoagulant drugs such as acetylsalicylic acid and warfarin. ${ }^{1,2}$

These patients should be referred to a hematologist for evaluation before surgical treatment. The risks of hemorrhage are directly associated with the kind of surgery and the etiology of the bleeding disorder. Conventional treatment of patients with hereditary disorders consists of replacement of clotting factors, administration of antifibrinolytic agents, and control of local bleeding. The treatment regimen of patients taking anticoagulants should be changed to prevent bleeding during and after the surgery. ${ }^{3}$

New techniques of local hemostasis with fibrin sealants, without replacement of clotting factors ${ }^{4,5}$ or anticoagulant dose adjustment ${ }^{6}$, have been successfully used in oral surgeries of patients with bleeding disorders.

Fibrin sealants, also called fibrin adhesives or glues, are plasma-derived products mimicking the last stage of blood clotting, resulting in the conversion of fibrinogen to fibrin. These products have hemostatic properties, but they act independently of the patient's coagulation pathway and contribute to the wound healing process. Fibrin sealants are either homologous or autologous products. ${ }^{7-9}$

Homologous fibrin sealants contain substances such as fibrinogen, factor XIII, aprotinin, thrombin, and calcium chloride. When these components are mixed, thrombin catalyses the conversion of fibrinogen to fibrin monomers and, in the presence of calcium ions, activates factor XIII. This factor, when activated by thrombin, converts fibrin monomers into a stable and insoluble fibrin clot. Aprotinin is an antifibrinolytic agent that inhibits or slows down the degradation of the clot. ${ }^{7-10}$
Autologous fibrin sealants have the same mechanism of action. However, the components are obtained from the patient's own plasma, and the thrombin used is of bovine origin. ${ }^{6,8}$

This report discusses a case of a maxillary right third molar extraction in a patient with von Willebrand's disease. Local hemostasis was obtained with homologous fibrin sealants and antifibrinolytic agents, without replacement of clotting factors.

\section{Case Report}

A female patient with von Willebrand's disease had to undergo extraction of a maxillary right third molar (Figure 1). The patient was referred to a hematologist for evaluation. It was determined the surgery should be performed with topical application of fibrin sealant and systemic administration of antifibrinolytic drugs.

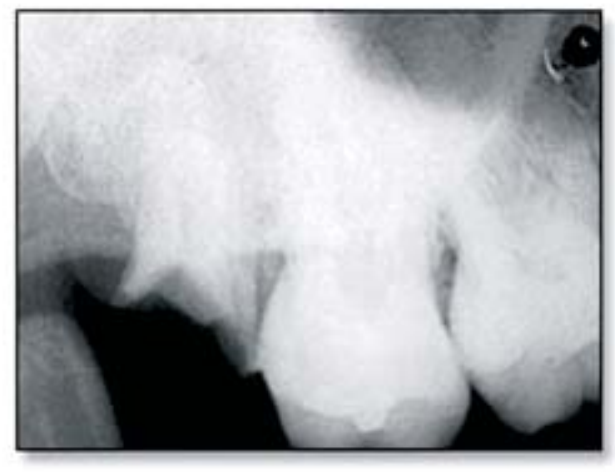

Figure 1. Preoperative radiograph of the maxillary right third molar.

One day before surgery, the patient was started on 2,000 mg tranexamic acid three times a day. After local anesthesia, the tooth was extracted with minimal trauma to the surrounding tissue. The socket was curetted and multiple sutures were applied to the soft tissue margins.

BERIPLAST $P^{\circledR}$ (Aventis Behring Gmbh, Marburg, Germany) fibrin sealant was applied to the dental socket. The product was supplied with two sets of components. Set one consisted of a transfer device and two vials containing aprotinin (vial A) and fibrinogen and factor XIII (vial B). Set two also consisted of a transfer device and two vials, one with calcium chloride (vial A) and the other with thrombin (vial B). The transfer devices were 


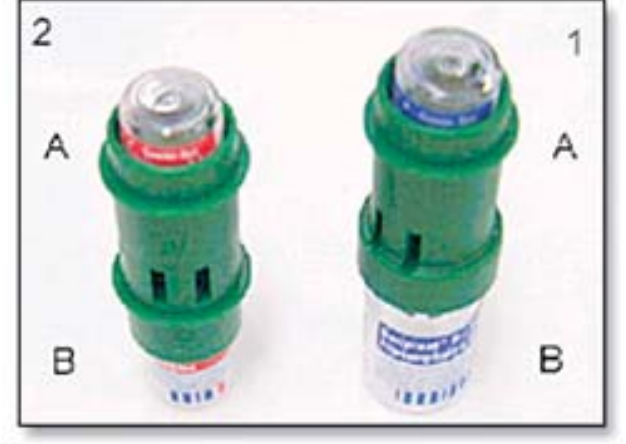

Figure 2. BERIPLAST $P^{\circledR}$ sets. Set one: transfer device, aprotinin (vial A), fibrinogen, and factor XIII (vial B). Set two: transfer device, calcium chloride (vial A), and thrombin (vial B). Pressure applied transfers the material in the top vial into the lower vial for reconstitution.

used to mix the substances in each set, and the mixtures were placed separately in two syringes (Figure 2).

A " $Y$ " tip was used to join these two syringes and form one double delivery device, which allowed the mixtures from each set to mix as they were injected into the socket. After application, local hemostasis was obtained immediately and excess material was removed (Figures 3 and 4).

After the surgery, the patient was instructed to take $750 \mathrm{mg}$ paracetamol four times a day for five days and to keep antifibrinolytic medication for seven days. The patient returned for postoperative control after two, seven, and 10 days. Sutures were removed on the tenth day. There was no bleeding or any other complication during follow-up.

\section{Discussion}

Carter et al. ${ }^{6}$ reported patients on anticoagulant therapy underwent dental extractions without changes in drug doses. Their patients' International Normalized Ratio (INR) values ranged from two to four on the day of the surgery (the INR was developed for the normalization of the protrombine value between different test centers). One group received topical treatment with autologous fibrin sealant, and the other was treated with an absorbable oxidized cellulose mesh in the dental socket and tranexamic acid mouthwash solution during and after the surgery.

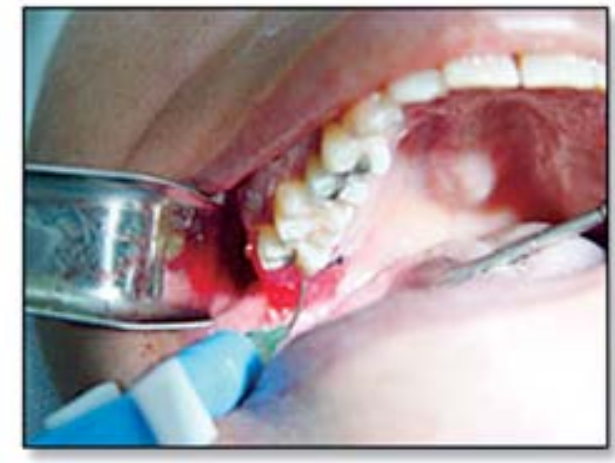

Figure 3. Double syringe with " $Y$ " tip. Application of the fibrin sealant.

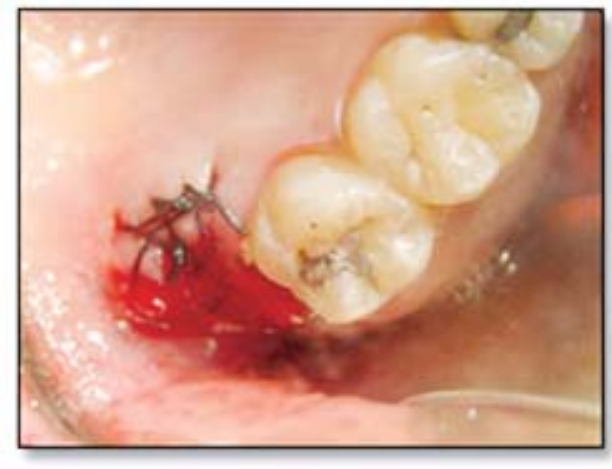

Figure 4. Removal of excess material. Local hemostasis.

Only two patients had postoperative bleeding. Both patients were in the autologous fibrin sealant group and had severe periodontal involvement of maxillary molar teeth.

Suwannuraks et al. ${ }^{5}$ used a fibrin sealant for tooth extraction in patients with hereditary or acquired bleeding disorders. Patients underwent surgery, application of the fibrin sealant in the socket, and subsequent adaptation of a celluloid splint. They were instructed to gently use a mouthwash after every meal for seven days and to take tranexamic acid three times a day for seven days in the postoperative period. Immediate hemostasis was observed in all patients. Only one patient with hemophilia developed excessive postoperative bleeding.

The benefits of fibrin sealants for local hemostasis in periodontal surgeries and dental extractions in patients with von Willebrand disease were evaluated by Federici et al. ${ }^{4}$ Tranexamic acid was prescribed for all patients, before and for seven 
days after the surgery. All patients received topical applications of fibrin sealants, and some were also given systemic desmopressin and clotting concentrates. Bleeding after surgery was observed in only two cases in both groups and was treated with additional applications of fibrin sealant.

In the case reported here topically-applied homologous fibrin sealant and tranexamic acid were used for a dental extraction in a patient with von Willebrand disease. Hemostasis was obtained immediately, and there was no bleeding in the postoperative period. The surgeon was prepared to perform additional interventions, such as reapplication of fibrin sealant and replacement of von Willebrand factor, if there were excessive bleeding during or after surgery.

\section{Conclusion}

Patients with hereditary or acquired bleeding disorders needing oral surgery should be referred to a hematologist for evaluation. New techniques of local hemostasis with fibrin sealants have yielded promising results. They reduce the need for replacement of clotting factors and associated complications as well as the cost of treatment. Patients undergoing anticoagulant therapy also benefit from this technique because surgery can be performed without changes in their treatment regimens.

\section{References}

1. Harmening DM. Clinical Hematology and Fundamentals of Hemostasis. 3rd ed. Philadelphia: Davis Company; 1997.

2. Medina RCS, Silveira JOL. Exodontia em Pacientes com Distúrbios Hemorrágicos. In: Silveira JOL, Beltrão GC. Exodontia. Porto Alegre: Médica Missau; 1998: 361-9.

3. Peterson LJ, Ellis E, Hupp JR, Tucker MR. Cirurgia Oral e Maxilofacial Contemporânea. 3rd ed. St. Louis: Mosby; 1998.

4. Federici AB, Sacco R, Stabile F, Carpenedo M, Zingaro E, Mannucci PM. Optimising local therapy during oral surgery in patients with von Willebrand disease: effective results from a retrospective analysis of 63 cases. Haemophilia2000; 6: 71-7.

5. Suwannuraks M, Chuansumrit A, Sriudomporn N. The use of fibrin glue as an operative sealant in dental extraction in bleeding disorder patients. Haemophilia1999; 5: 106-8.

6. Carter G, Goss A, Lloyd J. Tranexamic acid mouthwash versus autologous fibrin glue in patients taking warfarin undergoing dental extractions: a randomized prospective clinical study. J Oral Maxillofac Surg 2003; 61: 1432-5.

7. Fattahi T, Mohan M, Caldwell GT. Clinical applications of fibrin sealants. J Oral Maxillofac Surg 2004; 62: 218-24.

8. Soffer E, Ouhayoun JP, Anagnostou F. Fibrin sealants and platelet preparations in bone and periodontal healing. Oral Surg Oral Med Oral Pathol Oral Radiol Endod 2003; 95: 521-8.

9. Yücel EA, Oral O, Olgaç V, Oral CK. Effects of fibrin glue on wound healing in oral cavity. J Dent 2003; 31: 569-75.

10. Pacca FOT, Cavalcanti C, Saleh SM, Mazzoni A, Silva CEXSR, Cerri A. Adesivo fibrínico: proposta terapêutica para hemostasia. Robrac 2002; 11(32): 5-9. 
About the Authors

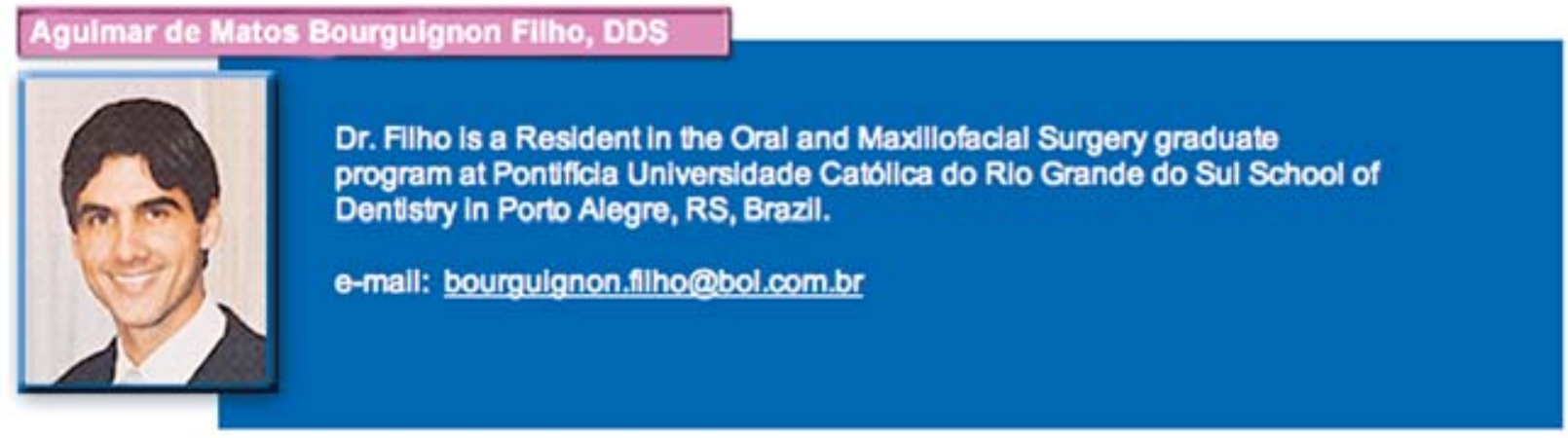

\section{Renato Schroder dos Santos, DDS}

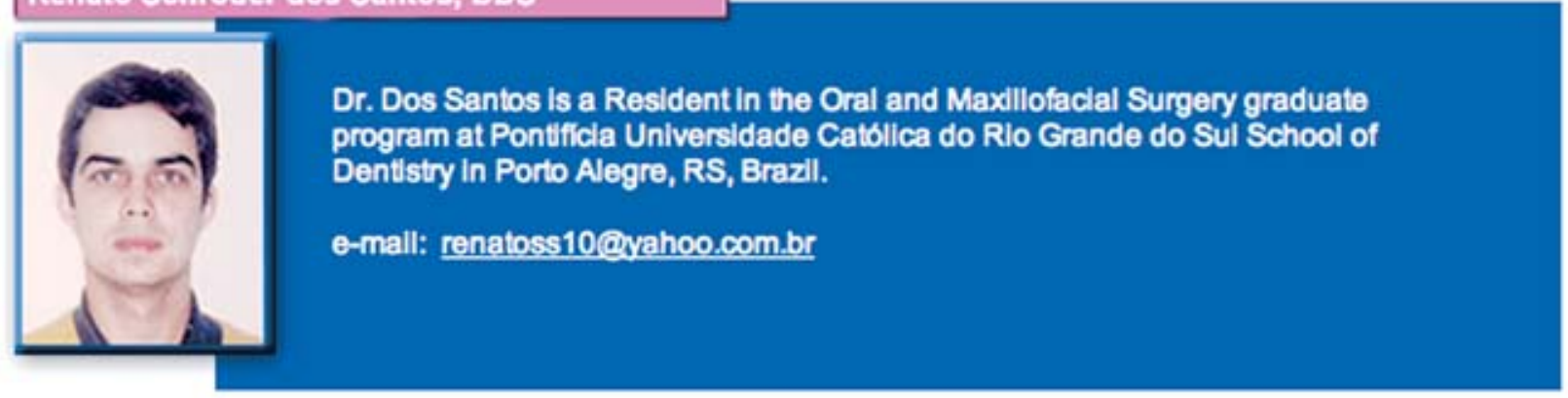

\section{Jose Renato Costa, DDS, PhD}

Dr. Costa is a Professor of Oral and Maxillofacial Surgery at the Universidade Federal do Espirito Santo School of Dentistry in Vitoria, ES, Brazll.

\section{Andre Alberto Camara Puppln, DDS, PhD}

Dr. Puppin is a Professor of Oral and Maxillofacial Surgery at the Universidade Federal do Espirito Santo School of Dentistry in Vitorla, ES, Brazll.

\section{Robson Almelda de Rezende, DDS, MS}

Dr. De Rezende is a Professor of Oral and Maxillofaclal Surgery at the Universidade Federal do Espirito Santo School of Dentistry in Vitorla, ES, Brazll.

\section{Gllson Correla Beltrdo, DDS, PhD}

Dr. Beltrato is a Professor In the Oral and Maxillofaclal Surgery graduate program at the Pontificla Universidade Catolica do Rlo Grande do Sul School of Dentlstry In Porto Alegre, RS, Brazll. 